\title{
Role of Hepatitis B virus X Protein in DNA Repair During Hepatocellular Carcinoma Development
}

\section{Hany A. Abdel-Hafiz*}

Department of Medicine, Division of Endocrinology, University of Colorado, Anschutz Medical Campus, Aurora, CO 80045-7113,USA

\begin{abstract}
Hepatocellular carcinoma (HCC) is the most lethal cancer in the world. Hepatitis B virus (HBV), hepatitis C virus (HCV), alcohol intake, and aflatoxin-B exposure have been identified as distinct causative factors for HCC. HBV infections play an important role in the development of $\mathrm{HCC}$. HBV X protein $(\mathrm{HBX})$ is a multifunctional protein that can modulate various cellular processes and plays a crucial role in the pathogenesis of HCC. HBx protein promotes cell cycle progression, inactivates negative growth regulators, and inhibits tumor suppressor genes such as p53. It has been shown recently that $\mathrm{HBx}$ modulates transcription of methyltransferases, causing regional hypermethylation of DNA that result in silencing of tumor suppressor genes. HBx is known to interact with DNA helicase components of transcription factor IIH (TFIIH), a basal transcriptional factor and an integral component of DNA excision repair results in interference of nucleotide excision repair. This review focuses on the role of HBx in DNA damage repair as well as its involvement in the regulation of various signaling pathways.
\end{abstract}

Keywords: Hepatitis B Virus; Hepatocellular Carcinoma; HBx protein; TFIIH; Transcriptional transactivation; DNA repair.

Abbreviations: Hepatitis B virus (HBV); Hepatocellular Carcinoma (HCC); Hepatitis C Virus (HCV); Transcription Factor IIH (TFIIH); Excision Repair Cross Complementing (ERCC); Nucleotide Excision Repair (NER); Xeroderma Pigmentosum (XP); Activator Protein-1 (AP-1); Fatty Acid Synthase (FAS); Mitogen Activated Protein Kinase (MAPK); Replication Protein A (RPA); Ultraviolet-DNA-Damaged Binding protein (UV-DDB); Tumor Necrosis Factor- $\alpha$ (TNF- $\alpha$ ).

\section{Introduction}

Hepatitis B virus (HBV) infection in humans is a major health problem and is one of the principal causative agents of liver disease. It is estimated that over 500 million individuals are infected with $\mathrm{HBV}$ worldwide and 1 million deaths are annually attributed to the effects of HBV infection [1-3]. The virus is associated with both acute and chronic liver diseases. Although the sequence of events in the development of hepatocellular carcinoma (HCC) remains poorly defined, a significant correlation has been made between long-term carriage of the virus and the development of HCC [1]. Modes of HBV infection are generally from mother to infant, by sexual routes and by using contaminated needles for injecting illicit drugs, tattooing, body piercing, or acupuncture. Several mechanisms by which HBV infection could lead to the development of HCC have been proposed. These mechanisms include insertional mutagenesis upon integration, trans-activation of the cellular genes, activation of signaling pathways, inactivation of tumor suppressor proteins, synergy with environmental carcinogenesis and host immune response.

One of the open reading frames of the HBV genome encodes a protein termed $\mathrm{HBx}$. $\mathrm{HBx}$ is required for viral infection and has been implicated in virus-mediated liver oncogenesis. The $\mathrm{HBx}$ protein has been detected in liver tissue from patients with chronic HBV infection, cirrhosis and hepatoma [4-9]. It is now generally acknowledged that $\mathrm{HBx}$ supplied in trans can increase gene expression of a wide variety of viral and cellular promoters and enhancer elements [10,11]. HBx has been shown to possess pleiotropic functions including impairment of cell cycle progression [12], interaction with transcription machinery
[8-11,13], and cell signal transduction and apoptosis mechanisms [1417]. Furthermore, $\mathrm{HBx}$ associated physically with $\mathrm{p} 53$ resulting in the sequestration of p53 in the cytoplasm [18], inhibition of p53 function including its DNA binding and transactivation activities [19] as well as p53 interaction with XPB protein [19]. Several studies suggested a potential role of $\mathrm{HBx}$ cellular DNA repair process. $\mathrm{HBx}$ has shown to directly bind the TFIIH components xeroderma pigmentosum complementation group $\mathrm{B}(\mathrm{XPB})$ and group $\mathrm{D}(\mathrm{XPD})$, which are required for basal transcription as well as for the strand-unwinding step of the core nucleotide excision repair (NER) [20,21]. It also binds to a probable DNA repair factor ultraviolet-DNA-damaged binding protein (UV-DDB) [22-24], p53 tumor suppressor protein [19,25], single stranded DNA (ss-DNA) [26], and UV-damaged DNA [27,28].

\section{Hepatocellular carcinoma}

Hepatocellular carcinoma (HCC) is a common malignancy and a leading cause of death worldwide. Recent epidemiological data have demonstrated that liver cancer incidence is continuously rising and will continue to do so for more than a decade, not only in Asia and Africa but also in North America and Europe [1]. HCC generally presents with poor prognosis, and no effective treatment is available for most HCC patients because this tumor remains refractory to current chemotherapeutic regimens [29]. However, HCC is frequently diagnosed when an advanced stage of the disease precludes local

*Corresponding author: Hany A. Abdel-Hafiz, PhD, Assistant Professor Department of Medicine/ Endocrinology, University of Colorado AMC, $12801 \mathrm{E}$ 17th Ave, MS 8106, Aurora, CO 80045-7113, USA, Tel: 303-724-3940; Fax: 303724-3920; E-mail: hany.abdel-hafiz@ucdenver.edu

Received August 16, 2011; Accepted October 27, 2011; Published October 29, 2011

Citation: Abdel-Hafiz HA (2011) Role of Hepatitis B virus X Protein in DNA Repair During Hepatocellular Carcinoma Development. J Carcinogene Mutagene S3:001. doi:10.4172/2157-2518.S3-001

Copyright: @ 2011 Abdel-Hafiz HA. This is an open-access article distributed unde the terms of the Creative Commons Attribution License, which permits unrestricted use, distribution, and reproduction in any medium, provided the original author and source are credited. 
ablative surgical interventions that could improve patient outcome. In this context, advances in our understanding of the molecular basis of HCC are urgently needed to develop early tumor markers and novel targeted agents with improved therapeutic efficiency [30,31].

Evidence has been provided for deregulation of various signaling pathways in HCC. Such as $\mathrm{Wnt} / \beta$-catenin signaling [32], the p53 pathway [33], transforming growth factor beta (TGF- $\beta$ ) signaling, Ras/MAPK signaling and PTEN/AKT and mTOR pathways [34]. Additionally, altered expression of growth factors such as HGF, IGFs and amphyregulin, as well as genes involved in angiogenesis may participate in the development and progression of HCC [35] (reviewed in reference [1]).

The role of DNA damage response during the early stages of carcinogenesis has been reported in many types of cancer [36]. Genomic instability is a characteristic feature of HCC and has been proposed to contribute to the malignant transformation [37-39]. DNA doublestrand break (DSB) constitutes a serious threat to genomic integrity. Inactivation of DSB repair is related to uncontrolled cell growth and increased cancer risk [40,41]. There has been compelling evidence that defective DSB repair accelerates live carcinogenesis [42-45]. It has been demonstrated that dysregulation of $\mathrm{Ku}$, the major component of DSB repair, renders hepatocytes sensitive to DNA damages induced by liver carcinogenesis [37]. A growing body of evidence further support a relationship between different $\mathrm{Ku}$ expression and HCC $[46,47]$. It has been shown recently that polymorphisms of XRCC5, Ku subunit, modulate the risk of development of HCC. In particular, the association were found more significant in $\mathrm{HBV}$ infected subjects than non-infected subjects [37].

\section{Hepatitis B virus (HBV)}

HBV is the prototype member of the Hepadnaviridae, a family of hepatotropic viruses. The genome of hepadnaviruses is a relaxed circular, partially doubled-stranded DNA genome that replicates via an RNA intermediate [48]. The HBV genome is around $3.2 \mathrm{~kb}$ in length and presents a highly compact genetic organization with 4 overlapping open reading frames (ORFs) that cover the entire genome. The pre$\mathrm{S} / \mathrm{S}$ ORF encodes the three viral surface proteins, the pre-C/C ORF encodes the e-antigen ( $\mathrm{HBeAg}$ ) and the core antigen ( $\mathrm{HBcAg}$ ), the $\mathrm{P}$ ORF encodes the terminal protein (TP) and the viral polymerase that possesses DNA polymerase, reverse transcriptase and $\mathrm{RNaseH}$ activities. The $\mathrm{X}$ gene encodes a small protein that is essential for virus replication but whose function remains partially understood. Finally, a viral protein termed HBSP has been shown to be encoded by a spliced viral transcript [49]. HBx is 154 amino acids in size, with a molecular mass of approximately $17.5 \mathrm{kDa}$. Comparative analyses of $\mathrm{HBV} \mathrm{X}$ gene sequences from mammalian hepadnaviruses of different species revealed areas of high conservation, including presumptive helical domains located in the amino and corboxy-terminal regions, and a potential coiled-coil motif $[50,51]$. Several groups have reported that $\mathrm{HBx}$ undergoes phosphorylation and acetylation when it was expressed in insect cells [52]. HBx is found to be located in the cytoplasm of cells and in the nucleolus (reviewed in [53]). HBx protein has been found to play an important role in HBV transcription and replication. Early studies have shown that $\mathrm{HBx}$ stimulates the activity of viral promoters and enhancers, and that the closely related virus WHV deficient for the expression of WHx cannot replicate in the animal host [54]. More recently, it was found that the replication of X-deficient HBV genomes was strongly compromised in established cell lines and in the mouse liver and that HBx provides in "trans" was able to restore HBV replication to wild-type levels [55-57]. In most studies, this effect has been attributed to the trans-activator activity of HBx protein (reviewed in [1]).

HBV DNA integration into human host chromosomes occurs in the infected liver since early stages of natural acute infections $[58,59]$. Multiple integrations have been detected in chronic hepatitis tissue $[60,61]$, and integrated HBV sequences have been seen in most (about 80\%) HBV-related HCC $[62,63]$.

\section{$\mathrm{HBx}$ and transcription factors}

$\mathrm{HBx}$ protein is multifunctional protein that can modulate various types of transcriptional factors (Figure 1). HBx does not bind directly to the DNA instead; HBx activates the transcription of host genes by its interactions with many transcription factors. The transactivation function of HBx may play an important role in HCC because it is involved in the activation of a large number of signaling pathways and cellular genes that are involved in oncogenesis, proliferation, inflammation and immune responses [64-66]. For example, it has been reported previously that $\mathrm{HBx}$ interacts with several basal transcriptional factors, such as transcription factor IIB (TFIIB), transcription factor IIH (TFIIH) [20,67], and RNA polymerase subunit RBP5 [68,69], tumor suppressor protein p53 [70,71], TATA binding protein (TBP) [72] and a putative DNA repair protein UV-DDB [23,73]. HBx interacts also with cAMP response element-binding protein (CREB), activating transcription factor-2 (ATF-2) [74-76], C/EBP and AP-2 to modify their activities [77]. It has been shown that HBx interacts with $\mathrm{CREB}$-binding protein $(\mathrm{CBP} / \mathrm{p} 300)$ to synergistically enhance CREB activity [66]. It has been shown that HBx increases CREB/ATF DNA-binding activity as well as to enhance the recruitment of $\mathrm{CBP} /$ p300 to CREB/ATF bound to cellular DNA $[66,78]$. The modulation of CREB/ATF activity by $\mathrm{HBx}$ represents an important aspect of $\mathrm{HBx}$ activities since the CREB/ATF family members play an essential role in liver metabolism and proliferation, and CREB has been implicated in HCC [79]. Furthermore, evidence has been presented to indicate that

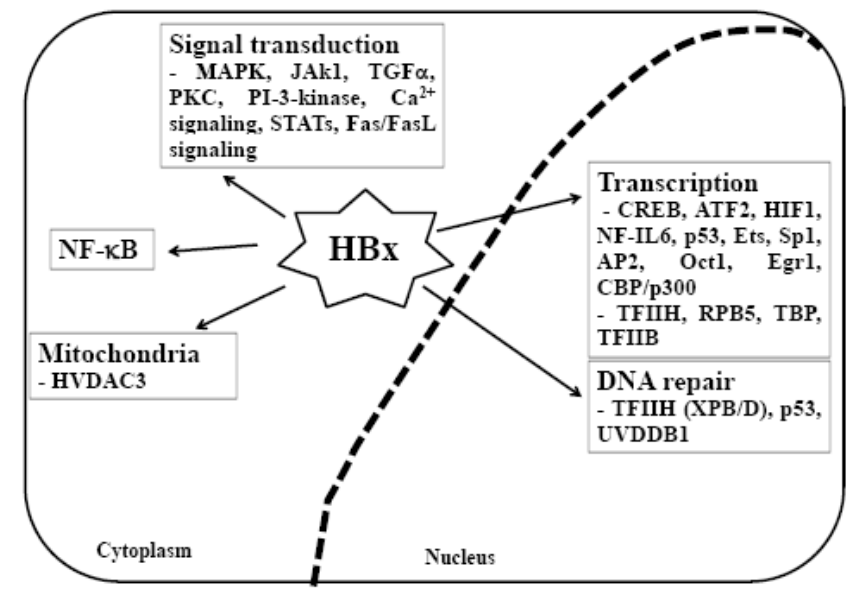

Figure 1: Signaling pathways regulated by $\mathrm{HBx}$. $\mathrm{HBx}$ can stimulate signal transduction pathways such as MAPK and NF-KB. HBx also binds to various protein targets such as transcription factors, coacivators and components of the basal transcription machinery. HBx may play an important role in DNA repair by interacting with TFIIH, UVDDB1 and p53. 
jun NH2-terminal kinase-dependent activation of ATF-2 plays a major role in the removal of cisplatin-induced DNA adducts via NER in human breast cancer cells [80]. Moreover, the coactivators CBP/p300 are known to bind and activate a large variety of cellular transcription factors [81]. Some of these factors, such as cJun, c-Fos and NF-KB are also activated by $\mathrm{HBx}$, and the interaction between $\mathrm{HBx}$ and $\mathrm{CBP} / \mathrm{p} 300$ could explain the broad activity of $\mathrm{HBx}$ on transcription. HBx has been shown to stimulate transcription by RNA Polymerase II and III [21,69]. Further, HBx was shown to induce either p53-mediated [15] or tumor necrosis factor alpha (TNFa)-mediated apoptotic destruction of liver cells [82-84].

\section{HBx and p53 Interaction}

p53 is a well-known tumor suppressor gene, and mutational inactivation of p53 function or deletion of the gene increases susceptibility to cancer. p53 protein levels are upregulated by a posttranslational mechanism in response to a range of stressor including DNA damage-inducing chemical compounds, UV irradiation, hypoxia and oncogenic viruses. p53 is a transcription factor that upregulates transcription of genes whose products block the cell cycle at G1/S phase boundary, thereby allowing repair of DNA lesions before DNA replication. Cells with irreparable damage are usually eliminated by p53-dependnet apoptosis [85]. HBx has been shown to inhibit [86-88] as well as induce $[16,89,90]$ apoptosis. The mechanism of regulation of apoptosis by $\mathrm{HBx}$ was reported to be via both p53-dependnet $[15,91]$ and p53-independnet [17] pathways. In the case of HCC the frequency of p53 mutations is not as high as those observed in other types of cancer, suggesting that there may be a unique mechanism for p53 inactivation in HCC.

It has been shown previously that $\mathrm{HBx}$ binds to the $\mathrm{C}$-terminus of p53 and induces its sequestration from the nucleus to the cytoplasm, thereby leading to inhibition of its effects on cell cycle arrest and DNA repair [92]. HBx also represses p53-mediated transcriptional activity, inactivates the sequence-specific DNA binding activity of p53 and the associations between $\mathrm{p} 53$ and the nucleotide excision repair gene products XPB and XPD [93]. HBx was shown to represses two components of the transcription-repair factor TFIIH, XPB, and XPD, both in p53-proficient and p53-deficient liver cells. This inhibition is observed while $\mathrm{HBx}$ maintains its transactivation function. Expression of $\mathrm{HBx}$ in liver cells results in down-regulation of endogenous XPB and $\mathrm{XPD} m \mathrm{mRNAs}$ and proteins. In liver tissue from $\mathrm{HBx}$ transgenics, $\mathrm{XPB}$ and XPD proteins are down-regulated in comparison to matched normal liver tissue [48]. The binding domain of $\mathrm{p} 53$ for interaction with HBx has been mapped to residues between 293 and 393. This region also binds XPB and XPD. It is therefore possible that HBx may interfere in the NER pathway by masking the p53 C-terminus and blocking p53 from binding to XPB and XPD [92] .

Transient HBx expression reduces global DNA repair in wildtype cells to the level of p53-null hepatocytes and has no effect on the repair of a transfected damaged plasmid [53]. Inhibition of p53mediated apoptosis by HBx may provide a clonal selective advantage for hepatocytes expressing this integrated viral gene during the early stages of human liver carcinogenesis [54].

\section{$\mathrm{HBx}$ and signaling pathways}

Recent studies have demonstrated that HBx possesses both cytoplasmic and nuclear specific activities. A number of cytoplasmic activities have been attributed to HBx including, the activation of Ras/
Raf/mitogen-activated protein (MAP) kinase, extracellular signalregulated kinase (ERK), MEKK1/Jun kinase [13], Janus kinase/STAT (JAK/STAT) and protein kinase $\mathrm{C}$ signal transduction pathways [94]. It was reported that activation of the Ras-MEK-MAPK pathway can antagonize the pro-apoptotic function of $\mathrm{HBx}$ [95]. Moreover, activation of the PI3K and SAPK/JNK pathways by HBx exerts antiapoptotic functions against transforming growth factor- $\beta$ (TGF- $\beta$ ) [88] and Fas/FasL signaling [96,97]. It has been shown that HBx can stimulate cellular calcium signaling pathways to release calcium ions into the cytosol, leading to activation of local adhesion kinase and proline-tyrosine kinase 2 and the subsequent activation of Src tyrosine kinases with their downstream Ras-Raf-MAPK signaling pathways $[98,99]$.

\section{HBX and DNA repair}

It has been shown that mice carrying $\mathrm{HBx}$ as a transgene show a direct correlation between the level of $\mathrm{HBx}$ expression and the likelihood to develop HCC $[100,101]$. However certain lineages of HBx transgenic mice do not exhibit tumor development unless coupled with other factors such as exposure to the hepatocarcinogen diethylnitrosamine [102] or when combined with $c$-myc induction [103]. It has been suggested previously that HBx does not directly cause cancer but plays a role in liver oncogenesis as a cofactor or tumor promoter [104]. Chronic HBV infection may present a longterm opportunity for an initiating event to occur, and HBx may act by modifying cellular regulatory/control mechanisms facilitating the culmination of the transformation process in the cell. In this regard, a highly probable tumor-initiating event is DNA damage.

DNA repair system is the primary defence against accumulation of mutations in genomic DNA and activation of cellular carcinogenesis. Deficiencies in DNA repair pathways have been linked to common cancer predisposition syndromes. Notable among these are the hereditary nonpolyposis colorectal cancer (HNPCC) and skin cancer or xeroderma pigmentosum (XP) $[105,106]$. DNA repair occurs by two different pathways: global repair removes DNA adducts from anywhere in the genome including from non-transcribed strand of active genes, where transcription coupled-repair removes DNA adducts from the transcribed strand of active genes [106-108]. Studies have demonstrated that some of the essential DNA repair proteins in yeast and mammalian cells are a part of basal transcription factor TFIIH $[67,108,109]$.

The nucleotide excision repair (NER) pathway is responsible for the repair of a number of DNA lesions [110]. NER is an enzymatic pathway involving more than 30 proteins, including the series XPA to XPG [111]. NER is initiated by the binding of XPA to damaged DNA in a process that is enhanced by the interaction of XPA with the single-stranded DNA-binding protein, RPA. XPA is a critical factor in NER because a deficiency of XPA results in a high sensitivity to killing by UV light. Although the XPA protein has no enzymatic activity, it functions as a core component in NER reactions by interacting with damaged DNA, RPA, ERCC1, DDB2, and TFIIH. Cells expressing XPA with a deletion of the binding to region for ERCC1, RPA70, or TFIIH [104,112] show UV-hypersensitivity. Following the lesion recognition events, the common "core NER pathway" is recruited and accomplishes error-free restoration of the DNA through sequential steps of: 1) strand unwinding mediated by the XPB and XPD helicases; 2) incision on either side of the lesion via the endonuclease activity of XPG and XPF; 3) excision of the lesion as part of a single-stranded oligonucleotide $\sim 30$ bp in length; and 4) DNA resynthesis and ligation, 
using normal DNA replication factors and undamaged complementary strand as template (Figure 2) [80].

In humans, the defects in XPD/ERCC2 and XPB/ERCC3 genes lead to xeroderma pigmentosum (XP) [113] and Cockayne's Syndrome (CS) $[105,107]$. Both conditions are manifested by the inability of the cells to efficiently repair damaged DNA.

HBx has been shown to enhance cell susceptibility to the cytotoxic effect of genotoxic agents, e.g. UVC and aflatoxins, that induce bulky adducts. This effect has been linked to impaired regulation of DNA repair and associated cell cycle checkpoint mechanisms [20,67,73,77], and/or the proapoptotic effect of HBx [114]. DNA damage induced by bulky adducts are preferred substrates for NER mechanism, where the TFIIH repair complex plays an essential role [82]. Inhibition of TFIIH activity by HBx may inhibit DNA repair and hence promote cells to undergo apoptosis. While several studies have focused on the transactivation capacity of the HBx protein in carcinogenesis, recent study showed that $\mathrm{HBx}$ is capable of transcriptional repression while maintaining it transactivation functions on NF-kB and AP1 responsive elements [115]. The implication of transactivation in carcinogenesis is demonstrated primarily in transient systems and there is evidence that $\mathrm{HBx}$-induced transactivation is not sufficient for cell transformation [116].

We have shown recently that $\mathrm{HBx}$ inhibits DNA repair pathway [117]. In the absence of UV damage, cells expressing $\mathrm{HBx}$ were found to be similar to control cells in cell growth measured by colony formation assay. Similar observations were reported by Lee and co-workers [104]. They demonstrated that HBx expression did not affect the morphology, viability, and cell cycle/apoptosis profiles or DNA repair machinery of UV-untreated HepG2 cells. However, HBx-expressing cells exhibited increased sensitivity to UV damage and reduced DNA repair capacity. The observation that $\mathrm{HBx}$ suppresses XPB and XPD in liver tissue

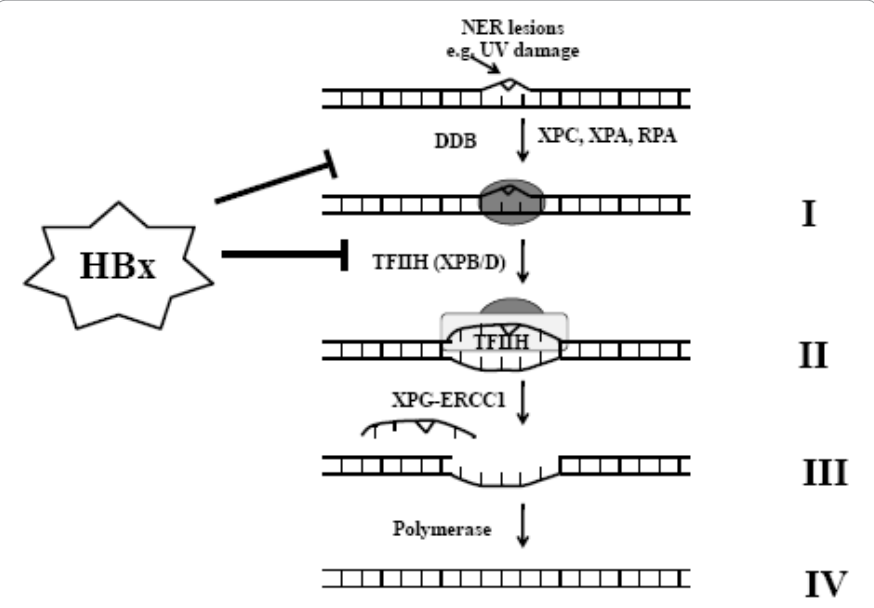

Figure 2: Model for HBx inhibition of NER. Three protein complexes are involved in DNA-damage recognition in NER pathway, XPA, XPC and RPA (I). These proteins recruits the transcription factor IIH (TFIIH) that incorporate two helicases XPB and XPD that unwind a 30 bp DNA fragment around the DNA damage (II). After DNA unwinding, damaged-DNA strand is excised by XPG and XPF-ERCC1 complex (III). After excision, damaged-DNA strand is removed and replaced by re-synthesizing the template complementary DNA strand by polymerase complex (IV). HBx inhibits NER by inactivating the DNA damagebinding (DDB) protein. HBx also downregulates the expression of XPB and XPD and interfering with TFIIH function leading to accumulation of errors, thereby contributing to $\mathrm{HCC}$ development. from HBx-transgenic mice supports the biological relevance of our recent findings [117]. XPB and XPD helicase and ATPase activities, but not the TFIIH kinase, are required for NER function [82-84,118]. The XPB and XPD proteins of the TFIIH complex are also involved in transcription-coupled repair [117]. Several transcription factors responsive elements are present in both XPB and XPD promoters, including Sp1. Sp1 transcription factor has been shown to be a specific target for $\mathrm{HBx}$ protein resulting in impairment of its DNA binding properties [12].

It has been shown previously that HBx protein interferes with NER through both p53-independnet and p53-dependnet mechanisms. $\mathrm{HBx}$ protein inhibits cell cycle checkpoint mechanisms required for DNA repair and binds to damaged DNA, interfering with NER and facilitating the accumulation of host DNA mutations $[119,120]$. HBx also binds to several cellular proteins known to be involved in DNA repair pathways including human homology of the UV-DDB [121].

It has been shown that pre-S1 and pre-S2 mutant HbsAG caused oxidative stress and DNA damage in Ground glass hepatocytes (GGHs), the pathological hallmarks for late phases of chronic HBV infection [122]. The DNA repair gene ogg1 was greatly induced by over-expression of pre-S mutant HbsAg. Other studies have reported that a defect in the ogg1 DNA repair gene is involved in various types of human carcinogenesis [123].

Previous studies showed that the $\mathrm{HBx}$ induced oxidative stress and high levels of ROS production, leading to oxidative DNA damage [124]. The DNA repair enzymes, human 8-oxoguanine DNA glycosylase 1 (hOGG1) and DNA glycosylase a (hMYHa) are crucial for repairing oxidative DNA damages. It has been shown recently that expression of $\mathrm{HBx}$ in non-tumor hepatic $\mathrm{LO} 2$ cells induced malignant transformation by promoting the accumulation of 8-hydroxydeoxyguanosine (8OHdG) in LO2/HBx cells, which was accompanied by significant lower levels of hMYHa, indicating the presence of $\mathrm{HBx}$-related oxidative DNA damage in human hepatic cells [125]. Therefore, efficient DNA repair for damaged DNA should play an important role in cancer prevention. These studies and our study [117] suggest that HBx may act as the promoting factor by inhibiting DNA repair causing DNA damage and accumulation of errors, thereby contributing to HCC development

\section{Mapping of the functional domains of $\mathrm{HBx}$}

Many studies showed that HBx plays an important role in HCC pathogenesis by interacting with cellular oncogenes [23,71,72] and that its functional domain involved in oncogenesis is at the middle of $\mathrm{HBx}$ protein $[20,73]$.

Tang and co-worker has mapped the coactivation domain within the C-terminal, two thirds of which (aa51-138) is identified to that of the transactivation. In contrast, the N-terminal of $\mathrm{HBx}$ has the ability to down regulate transactivation and was defined as the negative regulatory domain [126].

It has been shown recently that the $\mathrm{COOH}$-terminal truncated HBx plays a critical role in the HCC carcinogenesis via the activation of cell proliferation [127]. Alteration of HBV X gene has been detected more frequently in tissue samples of cirrhosis and/or HCC than in those of mild liver disease [128]. However, the mechanism of HBx in HCC carcinogenesis is still unclear, although many studies have associated it to ability of HBx trans-activating cellular oncogenes and signaling cascades that stimulate cell proliferation and lead to HCC 
Citation: Abdel-Hafiz HA (2011) Role of Hepatitis B virus X Protein in DNA Repair During Hepatocellular Carcinoma Development. J Carcinogene Mutagene S3:001. doi:10.4172/2157-2518.S3-001

carcinogenesis $[1,76,129-131]$. It has been demonstrated that the fulllength $\mathrm{HBx}$ contains two function domains: oncogenic domain (the $\mathrm{NH} 2$ terminal through middle peptide) and proapoptotic domain (the COOH-terminal peptide). There is a balance between these two functions in $\mathrm{HBV}$-infected hepatocytes. When the proapoptotic domain is deleted by an unknown mechanism during the viral integration, the balance is broken and the oncogenic function becomes dominant, leading to the subsequent development of HCC.

\section{Summary and Conclusions}

To date, a few mechanisms of HBV-induced HCC have been proposed. Early studies proposed that insertional mutagenesis of the HBV genome into human chromosomes might cause inactivation of tumor suppressor/proto-oncogenes [132-134]. However, later studies have shown that integration of $\mathrm{HBV}$ genome is genome-wide and unlikely attacks a specific tumor suppressor or proto-oncogene $[134,135]$. HBx initiates transactivation as well as induction of signal transduction pathways such as Ras/Raf-1 $[136,137]$.

It has been suggested that inhibition of DNA repair mechanisms by HBV products may contribute to observed synergestic interaction between chronic infection with $\mathrm{HBV}$ and exposure to liver carcinogenesis [37]. We have recently defined the inhibitory role of $\mathrm{HBx}$ in DNA excision repair process, thus hampering the cellular ability to repair the damaged DNA more effectively during $\mathrm{HBx}$ expression. Therefore, efficient DNA repair for damaged DNA should play an important role in cancer prevention. Our findings suggest that HBx may act as the promoting factor by inhibiting DNA repair causing DNA damage and accumulation of errors, thereby contributing to HCC development. As I described in this review, $\mathrm{HBx}$ has multifunctional role in the development of HCC. Cancer cells are often defective in both signaling and repair pathways. Understanding the effect of $\mathrm{HBx}$ on these two pathways could open ways to make tumours more vulnerable to combinational therapy.

\section{References}

1. Neuveut C, Wei Y, Buendia MA (2010) Mechanisms of HBV-related hepatocarcinogenesis. J Hepatol 52: 594-604.

2. Fung J, Lai CL, Yuen MF (2009) Hepatitis B and C virus-related carcinogenesis. Clin Microbiol Infect 15: 964-70.

3. Benhenda S, Cougot D, Buendia MA, Neuveut C (2009) Hepatitis B virus $X$ protein molecular functions and its role in virus life cycle and pathogenesis. Adv Cancer Res 103: 75-109.

4. Park EH, Koh SS, Srisuttee R, Cho IR, Min HJ, et al. (2009) Expression of HBX an oncoprotein of hepatitis $B$ virus, blocks reoviral oncolysis of hepatocellular carcinoma cells. Cancer Gene Ther 16: 453-461.

5. Mukherji A, Janbandhu VC, Kumar V (2009) HBx protein modulates PI3K/Akt pathway to overcome genotoxic stress-induced destabilization of cyclin D1 and arrest of cell cycle. Indian J Biochem Biophys 46: 37-44.

6. He Y, Sun HQ, He XE, Wang WL, Lei JH (2010) Knockdown of HBx by RNAi inhibits proliferation and enhances chemotherapy-induced apoptosis in hepatocellular carcinoma cells.

7. Cheng P, Li Y, Yang L, Wen Y, Shi W, et al. (2009) Hepatitis B virus X protein $(\mathrm{HBx})$ induces $\mathrm{G} 2 / \mathrm{M}$ arrest and apoptosis through sustained activation of cyclin B1-CDK1 kinase. Oncol Rep 22: 1101-1107.

8. Cheng B, Guo X, Zheng Y, Wang Y, Liu C, et al. (2009) The effects of HBx gene on the expression of DNA repair enzymes hOGG1 and hMYHalpha mRNA in HepG2 cells. J Huazhong Univ Sci Technolog Med Sci 29: 187-192.

9. Kuo CY, Wang JC, Wu CC, Hsu SL, Hwang GY (2008) Effects of hepatitis B virus $X$ protein $(\mathrm{HBx})$ on cell-growth inhibition in a CCL13-HBx stable cell line. Intervirology 51: 26-32.
10. Butel JS, Lee TH, Slagle BL (1996) Is the DNA repair system involved in hepatitis-B-virus-mediated hepatocellular carcinogenesis? Trends Microbiol 4 119-24.

11. Nassal M, Schaller H (1993) Hepatitis B virus replication. Trends Microbiol 1 : 221-228.

12. Benn J, Schneider RJ (1995) Hepatitis B virus HBx protein deregulates cell cycle checkpoint controls. Proc Natl Acad Sci U S A 92:11215-11219.

13. Han M, Yan W, Guo W, Xi D, Zhou Y, et al. (2008) Hepatitis B virus-induced hFGL2 transcription is dependent on c-Ets-2 and MAPK signal pathway. J Bio Chem 283: 32715-32729.

14. Shintani Y, Yotsuyanagi H, Moriya K, Fujie H, Tsutsumi T, et al. (1999) Induction of apoptosis after switch-on of the hepatitis $\mathrm{B}$ virus $\mathrm{X}$ gene mediated by the Cre/ loxP recombination system. J Gen Virol 80: 3257-3265.

15. Chirillo P, Pagano S, Natoli G, Puri PL, Burgio VL, et al. (1997) The hepatitis B virus $X$ gene induces $p 53-$ mediated programmed cell death. Proc Natl Acad Sci U S A 94: 8162-8167.

16. Bergametti F, Prigent S, Luber B, Benoit A, Tiollais $P$, et al. (1999) The proapoptotic effect of hepatitis B virus $\mathrm{HBx}$ protein correlates with its transactivation activity in stably transfected cell lines. Oncogene 18: 28602871.

17. Terradillos O, Pollicino T, Lecoeur H, Tripodi M, Gougeon ML, et al. (1998) p53independent apoptotic effects of the hepatitis $B$ virus $\mathrm{HBx}$ protein in vivo and in vitro. Oncogene 17: 2115-2123.

18. Iyer S, Groopman JD (2011) Interaction of mutant hepatitis B X protein with p53 tumor suppressor protein affects both transcription and cell survival. Mo Carcinog.

19. Wang XW, Forrester K, Yeh H, Feitelson MA, Gu JR, et al. (1994) Hepatitis $B$ virus $X$ protein inhibits $p 53$ sequence-specific DNA binding, transcriptional activity, and association with transcription factor ERCC3. Proc Natl Acad Sci U S A 91: 2230-2234.

20. Qadri I, Conaway JW, Conaway RC, Schaack J, Siddiqui A (1996) Hepatitis B virus transactivator protein, $\mathrm{HBx}$, associates with the components of TFIIH and stimulates the DNA helicase activity of TFIIH. Proc Natl Acad Sci U S A 93: 10578-10583.

21. Haviv I, Vaizel D, Shaul Y (1996) pX, the HBV-encoded coactivator, interacts with components of the transcription machinery and stimulates transcription in a TAF-independent manner. EMBO J 15: 3413-3420.

22. Lee TH, Elledge SJ, Butel JS (1995) Hepatitis B virus X protein interacts with a probable cellular DNA repair protein. J Virol 69:1107-1114.

23. Bontron S, Lin-Marq N, Strubin M (2002) Hepatitis B virus X protein associated with UV-DDB1 induces cell death in the nucleus and is functionally antagonized by UV-DDB2. J Biol Chem 277:38847-38854.

24. Hannan MA, Hellani A, Al-Khodairy FM, Kunhi M, Siddiqui Y, et al. (2002) Deficiency in the repair of UV-induced DNA damage in human skin fibroblasts compromised for the ATM gene. Carcinogenesis 23: 1617-1624.

25. Al-Mohanna MA, Al-Khodairy FM, Krezolek Z, Bertilsson PA, Al-Houssein KA et al. (2001) p53 is dispensable for UV-induced cell cycle arrest at late $G(1)$ in mammalian cells. Carcinogenesis 22: 573-578.

26. Qadri I, Ferrari ME, Siddiqui A (1996) The hepatitis B virus transactivato protein, $\mathrm{HBx}$, interacts with single-stranded DNA (ssDNA). Biochemical characterizations of the HBx-ssDNA interactions. J Biol Chem 271: 1544315450.

27. Capovilla A, Carmona S, Arbuthnot P (1997) Hepatitis B virus X-protein binds damaged DNA and sensitizes liver cells to ultraviolet irradiation. Biochem Biophys Res Commun 232: 255-260.

28. Al-Moghrabi NM, Al-Sharif IS, Aboussekhra A (2003) UV-induced de novo protein synthesis enhances nucleotide excision repair efficiency in a transcription-dependent manner in S. cerevisiae. DNA Repair (Amst) 2: 11851197.

29. Hu L, Chen L, Li L, Sun H, Yang G, et al. (2011) Hepatitis B virus X protein enhances cisplatin-induced hepatotoxicity via a mechanism involving degradation of Mcl-1. J Virol 85:3214-3228. 
Citation: Abdel-Hafiz HA (2011) Role of Hepatitis B virus X Protein in DNA Repair During Hepatocellular Carcinoma Development. J Carcinogene Mutagene S3:001. doi:10.4172/2157-2518.S3-001

30. Kew MC (2011) Hepatitis B virus $x$ protein in the pathogenesis of hepatitis $B$ virus-induced hepatocellular carcinoma. J Gastroenterol Hepatol 1: 144-152.

31. Keng VW, Tschida BR, Bell JB, Largaespada DA (2011) Modeling hepatitis $B$ virus $X$-induced hepatocellular carcinoma in mice with the Sleeping Beauty transposon system. Hepatology 53:781-790.

32. de La Coste A, Romagnolo B, Billuart P, Renard CA, Buendia MA, et al. (1998) Somatic mutations of the beta-catenin gene are frequent in mouse and human hepatocellular carcinomas. Proc Natl Acad Sci U S A 95: 8847-8851.

33. Hussain SP, Schwank J, Staib F, Wang XW, Harris CC (2007) TP53 mutations and hepatocellular carcinoma: insights into the etiology and pathogenesis of liver cancer. Oncogene 26: 2166-2176.

34. Villanueva A, Chiang DY, Newell P, Peix J, Thung S, et al. (2008) Pivotal role of mTOR signaling in hepatocellular carcinoma. Gastroenterology 135: 1972 1983.

35. Breuhahn K, Longerich T, Schirmacher $\mathrm{P}$ (2006) Dysregulation of growth factor signaling in human hepatocellular carcinoma. Oncogene 25: 3787-3800.

36. Matsuda $Y$, Ichida $T$ (2009) Impact of hepatitis $B$ virus $X$ protein on the DNA damage response during hepatocarcinogenesis. Med Mol Morphol 42: 138142

37. Li R, Yang Y, An Y, Zhou Y, Liu Y, et al. (2011) Genetic polymorphisms in DNA double-strand break repair genes XRCC5, XRCC6 and susceptibility to hepatocellular carcinoma. Carcinogenesis 32: 530-536.

38. Farazi PA, DePinho RA (2006) Hepatocellular carcinoma pathogenesis: from genes to environment. Nat Rev Cancer 6: 674-687.

39. Calvisi DF, Factor VM, Ladu S, Conner EA, Thorgeirsson SS (2004) Disruption of beta-catenin pathway or genomic instability define two distinct categories of liver cancer in transgenic mice. Gastroenterology 126: 1374-1386.

40. Khanna KK, Jackson SP (2001) DNA double-strand breaks: signaling, repair and the cancer connection. Nat Genet 27: 247-254

41. van Gent DC, Hoeijmakers JH, Kanaar R (2001) Chromosomal stability and the DNA double-stranded break connection. Nat Rev Genet 2: 196-206.

42. Tong WM, Cortes $U$, Hande MP, Ohgaki $H$, Cavalli LR, et al. Synergistic role of Ku80 and poly(ADP-ribose) polymerase in suppressing chromosomal aberrations and liver cancer formation. Cancer Res 62: 6990-6996.

43. Teoh NC, Dan YY, Swisshelm K, Lehman S, et al. (2008) Defective DNA strand break repair causes chromosomal instability and accelerates liver carcinogenesis in mice. Hepatology 47:2078-2088.

44. Hironaka K, Factor VM, Calvisi DF, Conner EA, Thorgeirsson SS (2003) Dysregulation of DNA repair pathways in a transforming growth factor alpha/cmyc transgenic mouse model of accelerated hepatocarcinogenesis. Lab Invest 83: $643-654$

45. Barash H, R Gross E, Edrei Y, Ella E, Israel A, et al. (2010) Accelerated carcinogenesis following liver regeneration is associated with chronic inflammation-induced double-strand DNA breaks. Proc Natl Acad Sci U S A 107:2207-2212.

46. Seimiya M, Tomonaga T, Matsushita K, Sunaga M, Oh-Ishi M, et al. (2008) Identification of novel immunohistochemical tumor markers for primary hepatocellular carcinoma; clathrin heavy chain and formiminotransferase cyclodeaminase. Hepatology 48:519-530.

47. Luk JM, Su YC, Lam SC, Lee CK, Hu MY, et al. (2005) Proteomic identification of Ku70/Ku80 autoantigen recognized by monoclonal antibody against hepatocellular carcinoma. Proteomics 5: 1980-1986.

48. Summers J, Mason WS (1982) Replication of the genome of a hepatitis B--like virus by reverse transcription of an RNA intermediate. Cell 29: 403-415.

49. Soussan P, Garreau F, Zylberberg H, Ferray C, Brechot C, et al. (2000) In vivo expression of a new hepatitis $B$ virus protein encoded by a spliced RNA. J Clin Invest 105: 55-60.

50. Colgrove R, Simon G, Ganem D (1989) Transcriptional activation of homologous and heterologous genes by the hepatitis $\mathrm{B}$ virus $\mathrm{X}$ gene product in cells permissive for viral replication. J Virol 63: 4019-4026.
51. Kodama K, Ogasawara N, Yoshikawa H, Murakami S (1985) Nucleotide sequence of a cloned woodchuck hepatitis virus genome: evolutional relationship between hepadnaviruses. J Virol 56: 978-986.

52. Urban S, Hildt E, Eckerskorn C, Sirma H, Kekulé A, et al. (1997) Isolation and molecular characterization of hepatitis B virus X-protein from a baculovirus expression system. Hepatology 26: 1045-1053.

53. Bouchard MJ, Schneider RJ (2004) The enigmatic X gene of hepatitis B virus J Virol 78: 12725-12734.

54. Zoulim F, Saputelli J, Seeger C (1994) Woodchuck hepatitis virus X protein is required for viral infection in vivo. J Virol 68: 2026-2030.

55. Leupin O, Bontron S, Schaeffer C, Strubin M (2005) Hepatitis B virus X protein stimulates viral genome replication via a DDB1-dependent pathway distinct from that leading to cell death. J Virol 79: 4238-4245.

56. Keasler VV, Hodgson AJ, Madden CR, Slagle BL (2007) Enhancement of hepatitis $B$ virus replication by the regulatory $X$ protein in vitro and in vivo. $J$ Viro 81: 2656-2662.

57. Keasler VV, Hodgson AJ, Madden CR, Slagle BL (2009) Hepatitis B virus $\mathrm{HBx}$ protein localized to the nucleus restores $\mathrm{HBx}$-deficient virus replication in HepG2 cells and in vivo in hydrodynamically-injected mice. Virology 390:122 129.

58. Lugassy C, Bernuau J, Thiers V, Krosgaard K, Degott C, et al. (1987) Sequences of hepatitis B virus DNA in the serum and liver of patients with acute benign and fulminant hepatitis. J Infect Dis 155: 64-71.

59. Yaginuma K, Kobayashi H, Kobayashi M, Morishima T, Matsuyama K, et al. (1987) Multiple integration site of hepatitis B virus DNA in hepatocellular carcinoma and chronic active hepatitis tissues from children. J Virol 61: 18081813.

60. Tanaka Y, Esumi M, Shikata T (1988) Frequent integration of hepatitis B virus DNA in noncancerous liver tissue from hepatocellular carcinoma patients. $J$ Med Virol 26: 7-14.

61. Boender PJ, Schalm SW, Heijtink RA (1985) Detection of integration during active replication of hepatitis B virus in the liver. J Med Virol 16: 47-54

62. Brechot C, Pourcel C, Louise A, Rain B, Tiollais P (1980) Presence of integrated hepatitis $B$ virus DNA sequences in cellular DNA of human hepatocellular carcinoma. Nature 286: 533-535.

63. Bréchot C, Gozuacik D, Murakami Y, Paterlini-Bréchot P (2000) Molecula bases for the development of hepatitis $B$ virus (HBV)-related hepatocellular carcinoma (HCC). Semin Cancer Biol 10: 211-231.

64. Rossner MT (1992) Review: hepatitis B virus X-gene product: a promiscuous transcriptional activator. J Med Virol 36: 101-117.

65. Cougot D, Neuveut C, Buendia MA (2005) HBV induced carcinogenesis. J Clin Virol 34 Suppl 1:S75-78.

66. Cougot D, Wu Y, Cairo S, Caramel J, Renard CA, et al. (2007) The hepatitis $B$ virus $X$ protein functionally interacts with CREB-binding protein/p300 in the regulation of CREB-mediated transcription. J Biol Chem 282: 4277-4287.

67. Jaitovich-Groisman I, Benlimame N, Slagle BL, Perez MH, Alpert L, et al. (2001) Transcriptional regulation of the TFIIH transcription repair components $\mathrm{XPB}$ and XPD by the hepatitis $\mathrm{B}$ virus $\mathrm{x}$ protein in liver cells and transgenic liver tissue. J Biol Chem 276: 14124-14132.

68. Cheong JH, Yi M, Lin Y, Murakami S (1995) Human RPB5, a subunit shared by eukaryotic nuclear RNA polymerases, binds human hepatitis $B$ virus $X$ protein and may play a role in $X$ transactivation. EMBO J 14: 143-150.

69. Le TT, Zhang S, Hayashi N, Yasukawa M, Delgermaa L, et al. (2005) Mutationa analysis of human RNA polymerase II subunit 5 (RPB5): the residues critical for interactions with TFIIF subunit RAP30 and hepatitis B virus X protein. $J$ Biochem 138: 215-224.

70. Wang JH, Yun C, Kim S, Chae S, Lee YI, et al. (2008) Reactivation of p53 in cells expressing hepatitis $B$ virus $X$-protein involves $p 53$ phosphorylation and a reduction of Hdm2. Cancer Sci 99: 888-893.

71. Park SG, Min JY, Chung C, Hsieh A, Jung G (2009) Tumor suppressor protein 
Citation: Abdel-Hafiz HA (2011) Role of Hepatitis B virus X Protein in DNA Repair During Hepatocellular Carcinoma Development. J Carcinogene Mutagene S3:001. doi:10.4172/2157-2518.S3-001

Page 7 of 8

p53 induces degradation of the oncogenic protein HBx. Cancer Lett 282: 229237

72. Qadri I, Maguire HF, Siddiqui A (1995) Hepatitis B virus transactivator protein $X$ interacts with the TATA-binding protein. Proc Natl Acad Sci U S A 92: 10031007.

73. Leupin O, Bontron S, Strubin M (2003) Hepatitis B virus X protein and simian virus $5 \mathrm{~V}$ protein exhibit similar UV-DDB1 binding properties to mediate distinct activities. J Virol 77: 6274-6283.

74. Choi CY, Choi BH, Park GT, Rho HM (1997) Activating transcription factor 2 (ATF2) down-regulates hepatitis $B$ virus $X$ promoter activity by the competition for the activating protein 1 binding site and the formation of the ATF2-Jun heterodimer. J Biol Chem 272:16934-16939.

75. Li B, Gao B, Ye L, Han X, Wang W, et al. (2007) Hepatitis B virus X protein (HBx) activates ATF6 and IRE1-XBP1 pathways of unfolded protein response. Virus Res 124: 44-49.

76. Maguire HF, Hoeffler JP, Siddiqui A (1991) HBV X protein alters the DNA binding specificity of CREB and ATF-2 by protein-protein interactions. Science 252: 842-844.

77. Seto E, Mitchell PJ, Yen TS (1990) Transactivation by the hepatitis B virus X protein depends on AP-2 and other transcription factors. Nature 344: 72-74.

78. Barnabas S, Hai T, Andrisani OM (1997) The hepatitis B virus X protein enhances the DNA binding potential and transcription efficacy of bZip transcription factors. J Biol Chem 272: 20684-20690.

79. Abramovitch R, Tavor E, Jacob-Hirsch J, Zeira E, Amariglio N, et al. (2004) A pivotal role of cyclic AMP-responsive element binding protein in tumor progression. Cancer Res 64:1338-1346.

80. Mathonnet G, Lachance S, Alaoui-Jamali M, Drobetsky EA (2004) Expression of hepatitis $B$ virus $X$ oncoprotein inhibits transcription-coupled nucleotide excision repair in human cells. Mutat Res 554: 305-318.

81. Lehrmann H, Pritchard LL, Harel-Bellan A (2002) Histone acetyltransferases and deacetylases in the control of cell proliferation and differentiation. Adv Cancer Res 86: 41-65.

82. Kim WH, Hong F, Jaruga B, Zhang ZS, Fan SJ, et al. (2005) Hepatitis B virus $X$ protein sensitizes primary mouse hepatocytes to ethanol- and TNF-alphainduced apoptosis by a caspase-3-dependent mechanism. Cell Mol Immunol 2: $40-48$.

83. Yang Y, Zheng L, Lv G, Jin X, Sheng J (2007) Hepatocytes treated with HBV $X$ protein as cytotoxic effectors kill primary hepatocytes by TNF-alpha-related apoptosis-induced ligand-mediated mechanism. Intervirology 50: 323-327.

84. Yi YS, Park SG, Byeon SM, Kwon YG, Jung G (2003) Hepatitis B virus $X$ protein induces TNF-alpha expression via down-regulation of selenoprotein $\mathrm{P}$ in human hepatoma cell line, HepG2. Biochim Biophys Acta 1638:249-256.

85. Schwartz D, Rotter V (1998) p53-dependent cell cycle control: response to genotoxic stress. Semin Cancer Biol 8: 325-336.

86. Su F, Schneider RJ (1996) Hepatitis B virus HBx protein activates transcription factor NF-kappaB by acting on multiple cytoplasmic inhibitors of rel-related proteins. J Virol 70: 4558-4566.

87. Gottlob K, Fulco M, Levrero M, Graessmann A (1998) The hepatitis B virus HBx protein inhibits caspase 3 activity. J Biol Chem 273: 33347-33353.

88. Shih WL, Kuo ML, Chuang SE, Cheng AL, Doong SL (2000) Hepatitis B virus X protein inhibits transforming growth factor-beta -induced apoptosis through the activation of phosphatidylinositol 3-kinase pathway. J Biol Chem 275: 2585825864.

89. Koike K, Moriya K, Yotsuyanagi H, Shintani Y, Fujie H, et al. (1998) Compensatory apoptosis in preneoplastic liver of a transgenic mouse model for viral hepatocarcinogenesis. Cancer Lett 134:181-186.

90. Sirma H, Giannini C, Poussin K, Paterlini P, Kremsdorf D, et al. (1999) Hepatitis $B$ virus $X$ mutants, present in hepatocellular carcinoma tissue abrogate both the antiproliferative and transactivation effects of HBx. Oncogene 18: 4848-4859.

91. Wang XW, Gibson MK, Vermeulen W, Yeh H, Forrester K, et al. (1995)
Abrogation of p53-induced apoptosis by the hepatitis B virus $X$ gene. Cancer Res 55:6012-6016.

92. Kew MC (2011) Hepatitis B virus $x$ protein in the pathogenesis of hepatitis $B$ virus-induced hepatocellular carcinoma. J Gastroenterol Hepatol Suppl 1:144152.

93. Wang XW, Yeh H, Schaeffer L, Roy R, Moncollin V, et al. (1995) p53 modulation of TFIIH-associated nucleotide excision repair activity. Nat Genet 10:188-195.

94. Kang-Park S, Lee JH, Shin JH, Lee YI (2001) Activation of the IGF-II gene by HBV-X protein requires PKC and p44/p42 map kinase signalings. Biochem Biophys Res Commun 283: 303-307.

95. Kim YC, Song KS, Yoon G, Nam MJ, Ryu WS (2001) Activated ras oncogene collaborates with $\mathrm{HBx}$ gene of hepatitis $\mathrm{B}$ virus to transform cells by suppressing HBx-mediated apoptosis. Oncogene 20:16-23.

96. Wang WH, Grégori G, Hullinger RL, Andrisani OM (2004) Sustained activation of p38 mitogen-activated protein kinase and c-Jun N-terminal kinase pathways by hepatitis $B$ virus $X$ protein mediates apoptosis via induction of Fas/FasL and tumor necrosis factor (TNF) receptor 1/TNF-alpha expression. Mol Cell Biol 24 10352-10365.

97. Diao J, Khine AA, Sarangi F, Hsu E, lorio C, et al. (2001) X protein of hepatitis $B$ virus inhibits Fas-mediated apoptosis and is associated with up-regulation of the SAPK/JNK pathway. J Biol Chem 276: 8328-8340.

98. Bouchard MJ, Wang LH, Schneider RJ (2001) Calcium signaling by HBx protein in hepatitis B virus DNA replication. Science 294:2376-2378.

99. Bouchard MJ, Puro RJ, Wang L, Schneider RJ (2003) Activation and inhibition of cellular calcium and tyrosine kinase signaling pathways identify targets of the HBx protein involved in hepatitis B virus replication. J Virol 77: 7713-7719.

100. Kim CM, Koike K, Saito I, Miyamura T, Jay G (1991) HBx gene of hepatitis B virus induces liver cancer in transgenic mice. Nature 351:317-320.

101. Koike K, Moriya K, Yotsuyanagi H, lino S, Kurokawa K (1994) Induction of cell cycle progression by hepatitis $\mathrm{B}$ virus $\mathrm{HBx}$ gene expression in quiescent mouse fibroblasts. J Clin Invest 94: 44-49.

102. Slagle BL, Lee TH, Medina D, Finegold MJ, Butel JS (1996) Increased sensitivity to the hepatocarcinogen diethylnitrosamine in transgenic mice carrying the hepatitis B virus X gene. Mol Carcinog 15: 261-269.

103. Terradillos O, Billet O, Renard CA, Levy R, Molina T, Briand P, et al. (1997) The hepatitis $B$ virus $X$ gene potentiates c-myc-induced liver oncogenesis in transgenic mice. Oncogene 14: 395-404

104. Lee AT, Ren J, Wong ET, Ban KH, Lee LA, et al. (2005) The hepatitis B virus X protein sensitizes HepG2 cells to UV light-induced DNA damage. J Biol Chem 280: 33525-33535.

105. Hoeijmakers JH (1994) Human nucleotide excision repair syndromes: molecular clues to unexpected intricacies. Eur J Cancer 30A: 1912-1921.

106. Wood RD (1996) DNA repair in eukaryotes. Annu Rev Biochem 65:135-167.

107. Chu G, Mayne L (1996) Xeroderma pigmentosum, Cockayne syndrome and trichothiodystrophy: do the genes explain the diseases? Trends Genet 12 187-192.

108. Selby CP, Sancar A (1993) Molecular mechanism of transcription-repair coupling. Science 260:53-58.

109. Lindahl T, Karran P, Wood RD (1997) DNA excision repair pathways. Curr Opin Genet Dev 7:158-169.

110. Taylor EM, Lehmann AR (1998) Conservation of eukaryotic DNA repair mechanisms. Int J Radiat Biol 74: 277-286.

111. Wood RD (1997) Nucleotide excision repair in mammalian cells. J Biol Chem 272: 23465-23468.

112.Zotter A, Luijsterburg MS, Warmerdam DO, Ibrahim S, Nigg A, et al. (2006) Recruitment of the nucleotide excision repair endonuclease XPG to sites of UV-induced dna damage depends on functional TFIIH. Mol Cell Biol 26: 88688879.

113. Al-Mohanna MA, Manogaran PS, Al-Mukhalafi Z, A Al-Hussein K, Aboussekhra 
Citation: Abdel-Hafiz HA (2011) Role of Hepatitis B virus X Protein in DNA Repair During Hepatocellular Carcinoma Development. J Carcinogene Mutagene S3:001. doi:10.4172/2157-2518.S3-001

Page 8 of 8

A (2004) The tumor suppressor p16(INK4a) gene is a regulator of apoptosis induced by ultraviolet light and cisplatin. Oncogene 23: 201-212.

114.Zhovmer A, Oksenych V, Coin F (2010) Two sides of the same coin: TFIIH complexes in transcription and DNA repair. ScientificWorldJournal 10: 633643.

115. Kim SY, Kim JC, Kim JK, Kim HJ, Lee HM, et al, (2008) Hepatitis B virus $X$ protein enhances NFkappaB activity through cooperating with VBP1. BMB Rep 41: 158-163.

116. Wang Z, Svejstrup JQ, Feaver WJ, Wu X, Kornberg RD, et al, (1994) Transcription factor $\mathrm{b}(\mathrm{TFIIH})$ is required during nucleotide-excision repair in yeast. Nature 368: 74-76.

117. Qadri I, Fatima K, AbdeL-Hafiz H (2011) Hepatitis B virus X protein impedes the DNA repair via its association with transcription factor, TFIIH. BMC Microbiol (2011) 11: 48.

118. Nakatake H, Chisaka O, Yamamoto S, Matsubara K, Koshy R (1993) Effect of $\mathrm{X}$ protein on transactivation of hepatitis $\mathrm{B}$ virus promoters and on viral replication. Virology 195: 305-314.

119. Bellamy CO, Clarke AR, Wyllie AH, Harrison DJ (1997) p53 Deficiency in liver reduces local control of survival and proliferation, but does not affect apoptosis after DNA damage. FASEB J 11: 591-599.

120. Bellamy CO (1997) p53 and apoptosis. Br Med Bull 53: 522-538.

121. Becker SA, Lee TH, Butel JS, Slagle BL (1998) Hepatitis B virus X protein interferes with cellular DNA repair. J Virol 72: 266-272.

122. Hsieh YH, Su IJ, Wang HC, Chang WW, Lei HY, et al. (2004) Pre-S mutan surface antigens in chronic hepatitis $B$ virus infection induce oxidative stress and DNA damage. Carcinogenesis 25: 2023-2032.

123. Shinmura K, Yokota J (2001) The OGG1 gene encodes a repair enzyme for oxidatively damaged DNA and is involved in human carcinogenesis. Antioxid Redox Signal 3: 597-609.

124. Waris G, Huh KW, Siddiqui A (2001) Mitochondrially associated hepatitis B virus $X$ protein constitutively activates transcription factors STAT-3 and NFkappa B via oxidative stress. Mol Cell Biol 21: 7721-7730.

125. Cheng B, Zheng Y, Guo X, Wang Y, Liu C (2010) Hepatitis B viral X protein alters the biological features and expressions of DNA repair enzymes in LO2 cells. Liver Int 30: 319-326.
126. Tang H, Oishi N, Kaneko S, Murakami S (2006) Molecular functions and biological roles of hepatitis B virus x protein. Cancer Sci 97: 977-983.

127. Ma NF, Lau SH, Hu L, Xie D, Wu J, et al. (2008) COOH-terminal truncated HBV X protein plays key role in hepatocarcinogenesis. Clin Cancer Res 14 5061-5068

128. Baptista M, Kramvis A, Kew MC (1999) High prevalence of 1762(T) 1764(A) mutations in the basic core promoter of hepatitis $B$ virus isolated from black Africans with hepatocellular carcinoma compared with asymptomatic carriers. Hepatology 29: 946-953.

129. Kekulé AS, Lauer U, Weiss L, Luber B, Hofschneider PH (1993) Hepatitis B virus transactivator $\mathrm{HBx}$ uses a tumour promoter signalling pathway. Nature 361: $742-745$

130.Doria M, Klein N, Lucito R, Schneider RJ (1995) The hepatitis B virus HBx protein is a dual specificity cytoplasmic activator of Ras and nuclear activator of transcription factors. EMBO J 14: 4747-4757.

131. Klein NP, Schneider RJ (1997) Activation of Src family kinases by hepatitis B virus HBx protein and coupled signaling to Ras. Mol Cell Biol 17: 6427-6436.

132. Hsu T, Möröy T, Etiemble J, Louise A, Trépo C, et al. (1988) Activation of c-myc by woodchuck hepatitis virus insertion in hepatocellular carcinoma. Cell 55: 627-635.

133. Takada S, Gotoh Y, Hayashi S, Yoshida M, Koike K (1990) Structural rearrangement of integrated hepatitis $B$ virus DNA as well as cellular flanking DNA is present in chronically infected hepatic tissues. J Virol 64: 822-828.

134. Buetow KH, Sheffield VC, Zhu M, Zhou T, Shen FM, et al. (1992) Low frequency of p53 mutations observed in a diverse collection of primary hepatocellular carcinomas. Proc Natl Acad Sci U S A 89: 9622-9626.

135. Urano Y, Watanabe K, Lin CC, Hino O, Tamaoki T (1991) Interstitial chromosomal deletion within 4q11-q13 in a human hepatoma cell line. Cancer Res 51: 1460-1464.

136. Natoli G, Avantaggiati ML, Chirillo P, Costanzo A, Artini M, et al. (1994) Induction of the DNA-binding activity of c-jun/c-fos heterodimers by the hepatitis B virus transactivator pX. Mol Cell Biol 14: 989-998.

137. Natoli G, Avantaggiati ML, Chirillo P, Costanzo A, Artini M, et al. (1994) Rasand Raf-dependent activation of c-jun transcriptional activity by the hepatitis $B$ virus transactivator $p X$. Oncogene 9: 2837-2843. 